
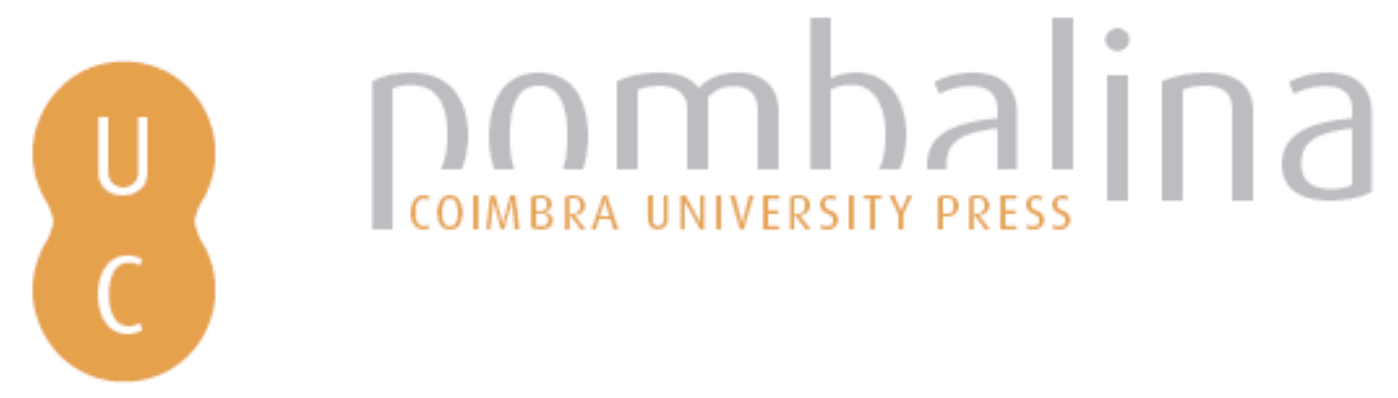

\title{
Ressonâncias albertianas: o problema do ornamento desde Adolf Loos
}

Autor(es): Rodrigues, José Miguel

Publicado por: Imprensa da Universidade de Coimbra

URL

persistente: $\quad$ URI:http://hdl.handle.net/10316.2/36680

DOI: $\quad$ DOI:http://dx.doi.org/10.14195/978-989-26-1015-3_18

Accessed : $\quad$ 26-Apr-2023 03:31:05

A navegação consulta e descarregamento dos títulos inseridos nas Bibliotecas Digitais UC Digitalis, UC Pombalina e UC Impactum, pressupõem a aceitação plena e sem reservas dos Termos e Condições de Uso destas Bibliotecas Digitais, disponíveis em https://digitalis.uc.pt/pt-pt/termos.

Conforme exposto nos referidos Termos e Condições de Uso, o descarregamento de títulos de acesso restrito requer uma licença válida de autorização devendo o utilizador aceder ao(s) documento(s) a partir de um endereço de IP da instituição detentora da supramencionada licença.

Ao utilizador é apenas permitido o descarregamento para uso pessoal, pelo que o emprego do(s) título(s) descarregado(s) para outro fim, designadamente comercial, carece de autorização do respetivo autor ou editor da obra.

Na medida em que todas as obras da UC Digitalis se encontram protegidas pelo Código do Direito de Autor e Direitos Conexos e demais legislação aplicável, toda a cópia, parcial ou total, deste documento, nos casos em que é legalmente admitida, deverá conter ou fazer-se acompanhar por este aviso.

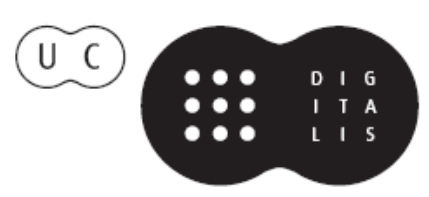


IMPRENSA DA

UNIVERSIDADE

DE COIMBRA

COIMBRA

UNIVERSITY

PRESS

\section{NA GÉNESE DAS RACIONALIDADES MODERNAS II}

Em torno de Alberti e do Humanismo

MÁRIO KRÜGER et alii

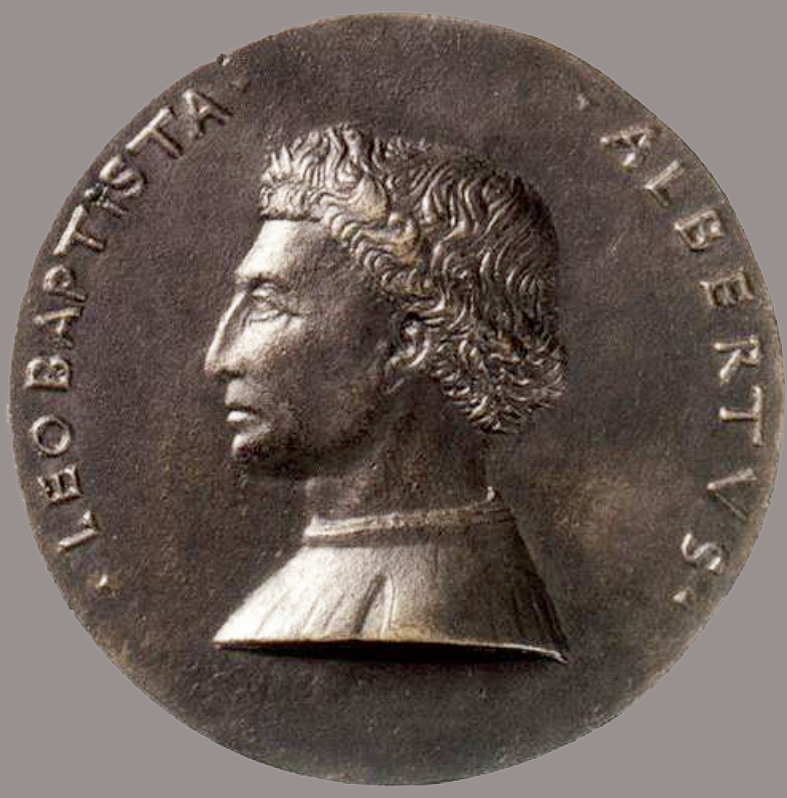




\title{
RESSONÂNCIAS ALBERTIANAS: O PROBLEMA DO ORNAMENTO DESDEADOLF LOOS
}

\author{
José Miguel Rodrigues
}

\section{Resumo}

Pelo menos desde Adolf Loos, o ornamento enquanto instrumento basilar da arquitetura como ofício tem sido posto em causa. A recusa da possibilidade de um ornamento moderno, a sua progressiva supressão na obra moderna e, por fim, o vaticínio da sua extinção absoluta, constituem, concomitantemente, fatores para o ressurgimento da ideia de ornamento que conhecemos a partir de Leon Battista Alberti: uma espécie de beleza auxiliar ou complementar, um atributo acessório, "acrescentado mais do que inato", em última instância, uma forma de corrigir aspetos defeituosos das obras quando a raridade da beleza inata não se manifesta e, também, podemos pensá-lo, uma forma de corrigir os edifícios a quem o Livro Décimo do De re aedificatoria é dedicado. Ernesto Nathan Rogers e, através dele, Giorgio Grassi - retomando ambos o problema do ornamento enquanto aspeto essencial e decisivo do ofício do arquiteto - constituem o testemunho do que propomos ver como ressonâncias albertianas.

Ornamento; Beleza; Moderno; Proporção.

\section{Résumé}

Au moins depuis Adolf Loos, l'ornement a été remis en cause, en tant qu'instrument basilaire de l'architecture comme métier. 
Le refus de la possibilité d'un ornement moderne, sa progressive supression dans l'œuvre moderne et, finalement, la prophétie de sa disparition absolue constituent, simultanément, des facteurs pour le resurgissement de l'idée de l'ornement telle qu'on l'a appris depuis Leon Battista Alberti: une espèce de beauté auxiliaire ou complémentaire, un attribut accessoire, "rajouté plutôt qu'inné", finalement une manière de corriger des aspects défectueux des œuvres quand la rareté de la beauté innée ne se manifeste pas. C'est aussi, on peut le penser, une manière de corriger les bâtiments auxquels le Dixième Livre du De re aedificatoria a été dédié. Ernesto Nathan Rogers et, à travers lui, Giorgio Grassi - reprenant tous les deux le problème de l'ornement en tant qu'aspect essentiel et décisif du métier d'architecte - constituent le témoignage de ce qu'on propose de voir comme des résonances albertiennes.

Ornement; Beauté; Moderne; Proportion.

\begin{abstract}
At least since Adolf Loos the ornament as a fundamental instrument of architecture considered as a métier has been called into question. The rejection of the possibility of a modern ornament, its gradual phasing out in modern buildings and, finally, the prediction of its absolute extinction, are, concomitantly, fators in the resurgence of ornament idea that we know from Leon Battista Alberti: a kind of beauty assist or complement, an accessory attribute, "added more than innate", ultimately, a way to correct defective aspects of the building when the rarity of the innate beauty is silent and, also, we can think, a way to step in buildings addressed in the Book Ten of the treaty. Adolf Loos and Ernesto Nathan Rogers and, through them, Giorgio Grassi - resuming the problem of ornament as a crucial and decisive aspect of the architect's métier - establish the testimony of what we propose to see as albertians resonances. Ornament; Beauty; Modern; Proportion.
\end{abstract}




\section{Abertura: ornamento albertiano}

Para Leon Battista Alberti o ornamento não foi, certamente, um problema menor. Uma simples contabilização da palavra ornamento nas entradas do índice do De re aedificatoria comprova a sua importância para o autor.

Uma releitura de algumas passagens escolhidas do tratado (a nosso ver, a este respeito decisivas) permitir-nos-á mostrar como o ornamento adquiriu uma caracterização singular - até aí nunca traduzida por escrito - possibilitando-lhe resistir até hoje enquanto instrumento insubstituível do projeto arquitetónico, mesmo depois do surgimento das vanguardas do movimento moderno.

Não será possível, todavia, compreender inteiramente o seu papel na teoria e na prática arquitetónicas de Alberti sem tomar em linha de conta três requisitos indispensáveis à estética albertiana.

O primeiro, é a elevação da venustas à condição de quinta-essência de entre os três vértices do triângulo vitruviano.

"Das três partes concluídas as duas primeiras, (...) resta a terceira" - a apetência para proporcionar graciosidade e sensação aprazível ${ }^{485}$ "de todas a mais nobre e a mais necessária." 486

Os efeitos desta consideração primordial da venustas são tão consideráveis que as suas consequências se estendem muito para além da importância conferida ao ornamento enquanto agente da venustas. Mário Krüger, por exemplo, refere como a subordinação da firmitas e utilitas à venustas demonstra como "apesar de não cessar de explorar, observar, medir e esboçar atentamente as obras do passado," a abordagem de Alberti “à Antiguidade Clássica é, essencialmente, arquitetónica e não

485 Reescrita da responsabilidade do autor utilizando as mesmas palavras referidas na passagem citada, mas, por uma questão de inteligibilidade da questão em apreço, recompondo a sua ordem.

LEON BATTISTA ALBERTI, Da Arte Edificatória [De Re Aedificatoria], (tradução do latim: Arnaldo Monteiro do Espírito Santo; introdução, notas e revisão disciplinar: Mário Júlio Teixeira Krüger), Lisboa, FCG, 2011, p. 375.

486 LEON BATTISTA ALBERTI, op. cit., p. 375. 
arqueológica, na medida em que se apresenta sempre com uma finalidade interventiva e prepositiva." 487

O segundo requisito da estética albertiana será a consideração da arquitetura enquanto arte racional e, terceiro, a consequente aceitação de que o juízo da venustas não é relativo.

“(...) quem edifica de modo a pretender a aprovação daquilo que edifica - como deve querer quem tem bom senso - deixa-se mobilizar por critérios racionais seguros; (...) Mas há quem não concorde com estes princípios e diga que é uma opinião inconstante e sem fundamento aquela com que emitimos um juízo acerca da beleza e de qualquer edificação e que a forma dos edifícios varia e muda ao bel-prazer de cada um, sem estar vinculada a nenhum preceito das artes. É comum este vício da ignorância: declarar que não existe aquilo que se desconhece. Estou determinado a eliminar este erro; (...)" 488

Ou seja, de acordo com esta terceira premissa, a apreciação da venustas - ou, à maneira kantiana, o juízo da beleza -, não sendo relativa. é discutível. Precisamente como o gosto - e até, sobretudo, por causa dele - que, como Maria Filomena Molder refere, Kant demonstrou "contra todas as aparências e contra um dito sábio popular cujo prazo ainda não cessou, [...] se há qualquer coisa que por inerência é para se discutir, essa qualquer coisa é o gosto." 489

Elevada, assim, a venustas, à dupla condição de mais importante e discutível (no equilíbrio das três forças do triângulo vitruviano) será a sua concinidade (palavra, diga-se, com grande mestria, recuperada na

487 Nota 998 de Mário Krüger: Leon Battista Alberti, Da Arte Edificatória [De Re Aedificatoria], op. cit., p. 375.

488 LEON BATTISTA ALBERTI, op. cit., p. 378, 379.

489 MARIA FILOMENA MOLDER, "Equivalências $e$ Intempestivas" (Introdução à Desumanização da Arte) in José Ortega Y Gasset, A Desumanização da Arte, Lisboa, Vega, 2000, p. 16.

Cf. JOSÉ MIGUEL RODRIGUES, O Mundo Ordenado e Acessível das Formas da Arquitetura, Tradição Clássica e Movimento Moderno, dois exemplos, Porto, Afrontamento, Fundação Marques da Silva, 2013, p. 376, 377. 
tradução portuguesa do De re aedificatoria) que guiará o processo "no jogo sábio, correto e magnífico dos volumes reunidos sob a luz, ${ }^{490}$ na expressão de Le Corbusier surgida cinco séculos mais tarde.

Mas, i.) em que consiste e ii.) como se obtém, para Alberti, a concinidade? E, por outro lado, respondidas estas duas questões: de que modo a concinidade pode ser reencontrada na Arquitetura Contemporânea, depois da anunciada morte do ornamento clássico? Ou, ainda, por último, parafraseando Mark Twain: terão sido as notícias da morte do ornamento clássico manifestamente exageradas?

Começando pelo princípio: em que consiste a concinidade? A resposta a esta questão por Alberti encontra-se no seu também mais citado aforismo que, apesar do contexto (entre tantos especialistas e devotos albertianos), não podemos deixar de recordar:

“(..) a beleza é a concinidade, em proporção exata, de todas as partes no conjunto a que pertencem, de tal modo que nada possa ser adicionado ou subtraído, ou transformado sem que mereça reprovação." 491

Ou, como durante anos, com base na minha própria tradução tendenciosa, de cor recitei aos estudantes de projeto:

“(..) a beleza é a harmonia entre todas as partes num todo organizado com base numa ideia precisa, de tal modo que nele nada se possa acrescentar, retirar ou modificar, sem que seja para pior.” ${ }^{492}$

Isto é, para Alberti a venustas é discutível - e, por isso, não relativa - e a sua indiscutibilidade - a beleza - um estatuto que lhe é conferido pela concinidade.

490 LE CORBUSIER, "Trois Rappels a Messieurs les Architectes" in Vers une Architecture, Paris, Éditions Vincent, Fréal \& C. ${ }^{a}, 1966$ ( $1^{\text {a }}$ ed. 1923), p. 16.

491 LEON BATTISTA ALBERTI, op. cit, p. 377.

492 Tradução livre a partir de: Leon Battista Alberti, L'Architettura [De Re Aedificatoria], (texto em latim e tradução ao cuidado de Giovanni Orlandi, introdução e notas de Paolo Portoghesi), Milano, Edizioni Il Polifilo, 1966 ( $1^{\text {a }}$ ed. 1485), tomo II, p. 446. 
(O caráter absoluto da concinidade albertiana pode parecer - mas não é - estranho ao princípio da discutibilidade do gosto, na medida em que, com o referido dito popular de que o gosto não se discute, o que se procura salvaguardar são as diferenças entre sujeitos ajuizadores que, assim, tornariam a beleza uma característica relativa - uma ideia a que Alberti abertamente se opunha - Estou determinado a eliminar este erro - foram as suas palavras. Ou, dito de outra maneira, a indiscutibilidade da beleza, proporcionada pela concinidade, precisa do pano de fundo do discutível para nele se poder manifestar.)

Respondida a primeira questão - em que consiste a concinidade? como propõe Alberti aspirar ao absoluto que ela representa? $\mathrm{O}$ autor delineia-nos dois caminhos habitualmente e no seu tempo concomitantes.

No livro sexto (o livro no tratado inteiramente dedicado ao ornamento em geral), a propósito da distinção entre beleza e ornamento - que conduzirá ao já referido aforismo a beleza é a concinidade - Alberti coloca a questão do que distinguirá a beleza do ornamento. ${ }^{493}$ A beleza faz nascer o magnífico e divino, raramente, porém, concedida, mesmo à própria natureza, notará Alberti:

"Quantos jovens ${ }^{494}$ belos existem em Atenas! - questiona, citando uma personagem de Cícero - E esse mesmo observador de formas entendia que, naqueles que não aprovava, faltava ou havia a mais alguma coisa que não condizia com as proporções da beleza. Isto foi-lhes conferido, se não me engano, pelos adornos acrescentados, disfarçando e encobrindo o que havia de disforme ou enfeitando e lustrando as partes mais belas, para que as desagradáveis fossem menos chocantes e as agradáveis deleitassem mais.” 495

493 Para acentuar a dificuldade da questão dirá: "Mas o que são em si mesmos a beleza e o ornamento ou em que se distinguem, talvez com mais clareza o entenderemos na alma do que eu sou capaz de explicar com palavras."

LEON BATTISTA ALBERTI, Da Arte Edificatória [De Re Aedificatoria], op. cit., p. 377.

${ }^{494}$ Por uma questão de apreensibilidade mais imediata, preferimos utilizar o vocábulo "jovens", em substituição da palavra "efebos" escolhida pelos tradutores da versão portuguesa. LEON BATTISTA ALBERTI, op. cit., p. 378.

495 LEON BATTISTA ALBERTI, op. cit., p. 377, 378. 
O que, muito significativamente, conduz Alberti à seguinte caracterização de ornamento:

"Assim, se isso for convincente, o ornamento será realmente uma espécie de luz subsidiária da beleza e como que o seu complemento. Daqui penso que se torna evidente que a beleza é como que algo de próprio e inato, espalhado por todo o corpo que é belo; ao passo que o ornato é da natureza do artificial e acrescentado mais do que do inato." 496

Ora é precisamente esta definição de ornamento que, apesar do seu caráter complementar, a torna um instrumento único e insubstituível da arte edificatória, ${ }^{497}$ como Mário Krüger nota, ao referir que:

"Na distinção entre beleza (pulchritudo) e ornamento (ornamentum), Alberti sugere que a primeira se relaciona com a dimensão global da obra e a segunda com a local, na medida em que esta é acrescentada e aquela é inerente ou inata. Em consequência, na sua teoria artística o ornamento assume um valor simultaneamente corretivo e complementar (...)."498

Ao tempo, a consideração subsidiária do ornamento teve, evidentemente, várias aplicações. Desde logo permitiu a recuperação - por assim dizer ornamental - dos elementos do mundo formal clássico, muito particularmente, da coluna: "em toda a arte edificatória o principal ornamento consiste sem dúvida nas colunas - afirmava Alberti." 499 Mas não só. As representações ornamentais, à superfície, a coluna, - isto é, a pilastra e a lesena ${ }^{500}$ (projeções planas da coluna) - foram certamente permitidas e encorajadas pela ideia de ornamento como elemento complementar e

496 LEON BATTISTA ALBERTI, op. cit, p. 378.

497 Título da versão portuguesa do tratado.

498 Ibidem p. 378.

499 Ibidem, p. 419.

500 Esta última, uma espécie de ícone da coluna, tão abstrato e bidimensional que, consuetudinariamente, perde a êntase imprescindível à coluna, dispensável à pilastra e à lesena e absolutamente desnecessária ao pilar, particularmente, ao pilar de secção quadrangular. 
corretivo da construção. Uma importância que, na arquitetura de Alberti, com facilidade, pode confirmar-se na sua obra construída: pense-se nas pilastras que desenham a fachada principal de Sant'Andrea de Mântua ou nas lesenas que conferem ritmo à "contextual" fachada do palácio Rucellai em Florença. Pense-se, ainda, nos inúmeros edifícios antigos com problemas construtivos e estruturais (alguns dos quais tão graves, como a basílica primitiva de São Pedro que ameaçava ruína) ${ }^{501}$ que, em paralelo com as ações de reforço estrutural, exigiam, igualmente, operações de redecoro ornamental como forma de dignificar a sua aparência formal, ocultando as marcas infligidas pelo tempo e amenizando os defeitos construtivos que este tinha posto a nu. É precisamente disso que Alberti nos fala quando, após descrever o longo e cuidadoso processo de reforço das paredes laterais da basílica de São Pedro, afirma:

"E não desprezamos a elegância da obra. Se acaso os muros forem de uma altura descomunal, aplica-lhes cornijas ou secções pintadas que dividam a altura em lugares apropriados. Se, porém, o muro for demasiado comprido, acrescenta-lhes de cima a baixo colunas - [ou pilastras ou lesenas, poder-se-ia também dizer]."502

Aquilo que hoje podemos ver e apelidar de estética albertiana ${ }^{503}$ apresenta, contudo, mais uma nuance que, na medida em que nos interessa identificar marcas evidentes do seu efeito ressonante, importa sem dúvida considerar. Referimo-nos a uma subdivisão, contemplada pelo próprio Alberti, quanto à origem da energia decorativa emanada pelo ornamento.

"Aquilo que agrada nas coisas mais belas e mais ornamentadas ou provém da invenção e dos raciocínios do engenho ou da mão do artífice, ou é implantado pela natureza nas próprias coisas. Pertencerá ao engenho a escolha, a distribuição, a disposição e outras ações do mesmo

\footnotetext{
501 Cf. Ibidem, p. 690.

502 Cf. Ibidem, p. 690, 691.

503 A teoria artística de Alberti nas palavras de Mário Krüger.
} 
teor que à obra possam conferir dignidade; à mão do artífice pertencerá acumular, aplicar, desbastar, talhar em redor, polir e outras ações do mesmo teor que à obra possam conferir graciosidade; atributos implantados nas coisas pela natureza serão o peso, a leveza, a densidade, a pureza, a resistência ao envelhecimento e outras qualidades semelhantes que à obra conferem admiração. (...)"504

Ou seja, em si mesmo, o ornamento pode ter atributos inatos que lhe são conferidos pela dimensão conatural do material, ou, em alternativa, o ornamento pode, por iniciativa e engenho humanos, adquirir um estatuto artificial, comparável ao do fabrico de artefatos humanos.

Ultrapassada a beleza inata de uma qualquer obra, o material base do ornamento, na medida em que foi extraído em bruto à natureza (a pedra, por exemplo), transporta desde logo consigo - e sem mais intervenções - uma parte ornamental, potencialmente bela (ou graciosa, nas palavras de Alberti) cujos atributos lhe foram infligidos pela natureza: o peso, $a$ leveza, a densidade a pureza, a resistência ao envelhecimento e outras que conferem admiração - isto é, por hipótese, o veio do mármore, não por acaso, apelidado pedra ornamental.

Afirmámos ao início que a teoria arquitetónica de Alberti nos punha à disposição dois caminhos distintos em direção à venustas habitualmente e no seu tempo concomitantes. O primeiro - perceber-se-á agora melhor que ao início - é o domínio do inato, isto é: a obra no que possui de imprescindível à sua auto-sustentação é bela sem precisar de mais cosmética. É o caminho mais raro, mais "natural" e, por isso, também, mais difícil de perseguir e alcançar: é, na nossa perspetiva, o caminho da mestria e do génio. O segundo é o do ornamento, isto é, um atributo complementar da beleza, acrescentado à obra pura, não inato e artificial. É um caminho extraordinariamente importante à praxis edificatória porque permite emendar a mão durante o decurso da obra. É extremamente humano, aberto ao reconhecimento do erro e potenciador do aperfeiçoamento: é na nossa perspetiva o caminho da acumulação da experiência

504 LEON BATTISTA ALBERTI, op. cit., p. 383. 
e da partilha dos conhecimentos adquiridos ao longo dos séculos, numa palavra, é a própria tradição.

Aliás, se - como proporemos - ornamento e decoração puderem ser considerados as duas faces da mesma moeda, o duplo significado do verbo decorar (simultaneamente querendo dizer ornamentar e fixar) terá certamente origem nesta ambiguidade de que ornamentar significa saber de cor e repetir o cânone fixado pela tradição, sem esquecer - como lembrou Siza - que repetir nunca é repetir. 505

Abordada a natureza do ornamento na teoria albertiana, valerá a pena analisar como na prática ela foi aplicada na obra construída do autor.

Observem-se os seguintes aspetos no Palácio Rucellai construído em Florença entre 1446 e 1451: i.) a sua fachada inacabada; ii.) a plausível relação deste fato com a praça que enquadra o palácio conferindo-lhe importância, dignidade e, sobretudo, escala; iii.) pense-se, por fim, no estranhamento que, um século depois, a solução albertiana continuava a provocar quando Giorgio Vasari o jovem (1562-1625) ousou desenhar uma versão "alternativa" - acabada - para a fachada do palácio Rucellai. Nela corrigiu a assimetria motivada pelo inacabamento da obra, talvez interpretando-a enquanto acidente de percurso no encontro do projeto ideal de Alberti com a realidade concreta da cidade. (Fig. 1 e 2)

Reflita-se, com mais empenho, sobre o estranhamento de Vasari o jovem perante o projeto semiconstruído de Alberti que terá conduzido à sua proposta corretiva para o palácio Rucellai (proposta corretiva na medida em que a sua ideia retoma e mantém os mesmos elementos compositivos que caracterizam a proposta albertiana: a lesena, o entablamento, a janela de dois lumes, o simulacro da estereotomia da pedra que desenha o pano de fundo da fachada, etc.). A sua alteração processa-se fundamentalmente a dois níveis: i.) ao nível da dimensão do módulo base usado na

505 ÁLVARO SIZA, "Repetir nunca é repetir" em Imaginar a Evidência, Lisboa, Edições 70, 1998, p. 15 . 
composição da fachada; e ii.) ao nível do regime da alternância adotado entre módulos com, ou sem porta, isto é, o que no projeto ideal (mas construído) de Alberti se traduz na modulação a-a-b-a-a-b-a-a' (em que $a^{\prime}$ é um módulo $a$ virtual - iniciado, mas não completamente terminado) tem correspondência, no projeto idealizado (mas não construído) de Vasari o jovem, na modulação a-b-a-a-a-b-a (em que $a$ é um módulo com porta e $b$ sem porta).

Independentemente da validade e das razões que explicam a proposta alternativa (estaria o autor incrédulo quanto à qualidade da proposta albertiana? pensaria que, inacabada, teria perdido a sua concinidade?) a verdade é que Vasari o jovem continua a equacionar o ornamento a partir dos mesmíssimos princípios de Alberti: isto é, como instrumento potencialmente corretivo e enquanto recurso secundário, não inato, capaz de restituir a beleza, na perspetiva de Vasari o jovem, perdida. Ou seja, não só os elementos compositivos são os mesmos - as lesenas, os entablamentos, o almofadado, etc., como o efeito pretendido - a beleza através do ornamento superficial da fachada -, os instrumentos desse efeito - o ritmo, a modulação e a proporção - e a estratégia global do desenho do alçado - em três estratos com ordens de lesenas sobrepostas - são precisamente os mesmos (a proposta de Vasari o jovem é na verdade um redesenho idealizado, enquanto a de Alberti, na medida em que permaneceu inacabada, um desenho ideal).

Regresse-se, todavia, à proposta do próprio Alberti - que, como refere Domingos Tavares, ${ }^{506}$ reveste a parede neutra do palácio numa relação com o seu interior não determinante - e reconheça-se como, nela, a prioridade é dada à relação com a cidade e à sua dimensão pública representada na praça e na loggia Rucellai - aí residindo precisamente a sua singularidade e, talvez, até, uma das suas principais qualidades.

A dimensão ornamental deste projeto surge, assim, por duas vias: a.) no desenho de pormenor dos elementos ornamentais envolvidos na composição, isto é, nomeadamente, na conceção dos temas formais

506 DOMINGOS TAVARES, Leon Baptista Alberti, teoria da arquitetura, Porto, Dafne, 2004, p. 101. 
que desenham os capiteis de ordens sobrepostas que percorrem toda a fachada; b.) mas, também, no conjunto resultante que é a fachada do palácio que surge delineada de acordo com uma modulação precisa, na qual repetição e diferença se constituem enquanto materiais do projeto de arquitetura e da arquitetura da cidade: a repetição resultado da reprodução de módulos enquadrados por lesenas e entablamentos; e a variação dada pela opção no piso térreo: entre i.) porta ou ii.) janela encimada por soco-banco junto ao chão.

Em suma, na proposta de Alberti, em qualquer dos casos referidos, a.) mera composição ornamental da superfície da fachada e b.) desenho "desejável” da cidade a partir dessa composição "inacabada" - o ornamento é usado como atributo complementar à obtenção da beleza. Assim sendo, porém, o que distingue as duas propostas e, sobretudo, qual a mais bela? Na nossa perspetiva, é evidente, a proposta de Alberti. Não só, nela, a concinidade é mais complexa - parte (palácio) e todo (cidade) foram tornados inseparáveis - como é igualmente mais completa - a concinidade do palácio e a concinidade da cidade foram inextricavelmente implicadas uma na outra. Uma observação de outro ângulo poderá todavia inclinar-se para a solução acabada de Vasari o jovem, aparentemente mais conseguida, ou seja, menos problemática do que a "inacabada" de Alberti. Esta inclinação, contudo, ao retirar da concinidade albertiana dois elementos - a praça e a loggia Rucellai - altera para pior a solução global do projeto da fachada do palácio Rucellai.

\section{Adolf Loos: ornamento clássico}

Durante os quatro séculos seguintes, e apesar da estética albertiana muitas vezes, e por longos períodos, ter sido posta em causa, a sua visão do ornamento permaneceu crucial em todos os desenvolvimentos futuros, mais ou menos clássicos. No Maneirismo, o ornamento afastou-se da tradição e adquiriu o estatuto de marca de água do artista. No Barroco, foi elevado à categoria de beleza primordial ao nível da venustas inata. No Romantismo, procurou outras origens - não-clássicas. No Neoclassicismo 
um novo regresso às origens - clássicas. E com a Arte Nova e os artistas da Secessão a procura, por fim, de um novo ornamento moderno.

Adolf Loos nasce, assim, no fim de um longo ciclo que encontra na industrialização acelerada do final do século XIX e nas revolucionárias vanguardas artísticas do início do século $\mathrm{XX}$ os ingredientes de uma radical transformação que se anuncia.

Adolf Loos é habitualmente responsabilizado pela morte do ornamento clássico. Nesta atribuição - a nosso ver claramente exagerada - valoriza-se uma leitura sectária e finalista do seu, não por acaso, mais célebre escrito - Ornamento e Delito - refira-se, muitas vezes erroneamente pronunciado Ornamento é delito. ${ }^{507}$ Neste texto de 1908 - admito - Loos avançou com uma denúncia - não contra todo o ornamento, como habitualmente se diz - mas contra o ornamento estéril e inútil. Como refere Aldo Rossi, para Loos, "o ornamento é delito, não por moralismo abstrato, mas antes quando se revela uma forma de idiotez, de degeneração, de repetição inútil."508

Refira-se que, também neste ponto, é possível estabelecer um paralelo com Alberti na sua crítica do ornamento como meio de ostentação:

“(...) Com o crescimento do império cresceu tanto o luxo (...) na cidade que (...) houve alguém da família dos Gordianos que construiu uma casa na via Prenestina com duzentas colunas com o mesmo fuste e igual tamanho, cinquenta das quais (...) mumídicas, cinquenta claudianas, cinquenta simíades [e] cinquenta tisteias. E que dizer em relação àquilo que Lucrécio menciona? Pela casa havia estátuas de ouro. Que na mão direita seguravam tochas acesas, para darem luz aos banquetes noturnos. A que propósito vem isto tudo? A fim de que, com o exemplo deles, eu fundamente aquilo que em outro lugar dissemos: que agrade aquilo que é à medida da dignidade de cada um. E se me ouvires,

507 ADOLF LOOS, "Ornamento y Delito" ("Ornament und Verbechen", Conferência de 1908, primeira edição desconhecida, publicado em Caibers d'aujourd'bui em 1913, publicado no Frankfurt Zeitung em 1929) in Escritos I (Adolf Opel, Josep Quetglas, eds.), Madrid, El Croquis Editorial, 1993, p. 346-355.

508 ALDO ROSSI, "La Arquitetura de Adolf Loos" in Benedetto Gravagnuolo, Adolf Loos, teoria y obras, Madrid, Nerea, 1988 (1. ${ }^{a}$ ed. 1981), p. 15. 
prefiro que, nos edifícios privados, aos mais ricos falte alguma coisa que contribua para o ornamento, a que os mais pobres e mais poupados critiquem o luxo dos ricos (...). E, embora declarando que devem ser censurados aqueles que excedem os limites, considero, todavia, dignos de maior censura aqueles que edificarem com tão grandes gastos (...) que as suas obras não possam ser ornamentadas (...)"509

Isto é, para Alberti - como para Loos - o ornamento criticável é o ornamento inútil (e Loos também constrói a sua crítica a partir do excesso e do desperdício), mas, porém no final, para Alberti - como também para Loos - uma das razões para evitar o excesso é justamente dar lugar ao ornamento (como parece plausível, desejavelmente, também não excessivo).

A não ser assim - isto é, se Loos estivesse de fato contra todo o ornamento - que sentido dar às suas igualmente afirmativas declarações a favor do ornamento, em especial clássico:

"A nossa educação baseia-se na formação clássica. Um arquiteto é um pedreiro que estudou latim. Os arquitetos modernos parecem contudo ser esperantistas. O ensino do desenho deve nascer do ornamento clássico."

"E, por isso, pensamos que o arquiteto do futuro deverá ter uma formação clássica. Com efeito, pode-se desde logo afirmar que, de entre todas as profissões, a arquitetura será a que exige a mais rigorosa instrução clássica. Mas, por outro lado, para se ajustar às necessidades materiais do seu tempo, ele deverá [também] ser um homem moderno."511

Ou seja, para Loos o ornamento clássico está moribundo, mas não morto. Fará tão pouco sentido mantê-lo nesse estado de letargia agonizante, como assassiná-lo. A saída para este impasse - que constitui a principal encruzilhada que indicará o caminho à arquitetura do Movimento

509 LEON BATTISTA ALBERTI, op. cit., p. 574, 575.

510 ADOLF LOOS, "Ornamento y Educacion, Respuesta a una Encuentra" ("Ornament und Erziehung" originalmente publicado na Wohnungskultur, n. ${ }^{\circ} 2 / 3,1924$ ) in Escritos II (Adolf Opel, Josep Quetglas, eds.), Madrid, El Croquis Editorial, 1993, p. 218.

511 ADOLF LOOS, "La Vieja Tendencia y la Nueva en el Arte de Construir", p. 125. 
Moderno - na sua perspetiva, só poderá ser uma de duas. O ornamento clássico, ou não tem substituto moderno (a sua tese em Ornamento $e$ Delito), ou só encontrará substituto quando representar um avanço (a sua tese aperfeiçoada em Ornamento e Educação):

"Não há mudanças conscientes? questiona - Também existem. Os meus alunos sabem que é possível uma mudança sempre e quando ela implique um aperfeiçoamento da forma antiga. (...) As novas descobertas produzem grandes ruturas na tradição, na construção tradicional." 512

Apesar desta ideia, Loos salvaguarda duas importantíssimas condições. Primeira: que o ornamento sincero dos artesãos seja salvaguardado - o sentido da sua pequena história sobre o sapateiro (que ficaria infeliz se lhe encomendarmos um par de sapatos sem "furinhos", ainda que com um honorário maior). Segunda: que a progressiva desornamentação dos artefatos e da arquitetura (implícita na sua teoria do ornamento) não se transforme em mais uma roupagem estilística (com estilo queriam dizer ornamento - criticava Loos os que lamentavam que a sua época não tivesse um estilo).

Se tivermos razão, Loos não prescinde do ornamento na sua teoria da arquitetura. Mas mais, ao mesmo tempo que para ele o ornamento é clássico, a desornamentação só fará sentido se for progressiva, isto é, quando não impedir a felicidade do artesão e representar um aperfeiçoamento. Por outro lado, a transformação do ornamento clássico segue esta última regra. Por isso, como os romanos foram capazes de aperfeiçoar a ordem dórica grega dotando-a de base - assim criando a ordem dórica romana - ou aperfeiçoar todas as ordens clássicas dotando-as de pedestal (sempre que a escala o exigisse), também Loos propõe o seu

512 Noutra edição, esta afirmação de Loos surge com a seguinte formulação, porventura, mais elucidativa:

"Mis alumnos saben que es possible un cambio siempre y cuando implique un perfeccionamiento en la forma antigua". Isto é: "Os meus alunos sabem que é possível uma mudança sempre e quando ela implique um aperfeiçoamento da forma antiga".

ADOLF LOOS, "El Arte Popular ("Heimat Kunst)" in Adolf Loos, Ornamento y Delito y Otros Escritos, p. 235. 
aperfeiçoamento: a coluna dórica grega - sem base e - monumentalizada através de um pedestal com a escala da cidade corrente - a sua proposta de arranha-céus para o concurso do Chicago Tribune. 513

\section{Ernesto Nathan Rogers: ornamento moderno}

Se perscrutarmos mais ressonâncias albertianas a este propósito, à medida que nos afastamos do século XIX e de Adolf Loos, deparamo-nos com uma dificuldade crescente em encontrar autores-arquitetos para quem este problema permaneça crucial e decisivo. Ernesto Nathan Rogers constitui porém, deste e de outros pontos de vista, uma extraordinária exceção à regra. Para este autor, sem ornamento não há decoração, ao mesmo tempo que sem a sua energia não há arquitetura.

"O ornamento é a exteriorização formal da energia decorativa, em todas as suas aceções, como a palavra na poesia; os frisos são só um dos aspetos desta exteriorização e ocupam um lugar análogo ao da rima nos poemas.

Muitos são os que pensam que a arquitetura moderna não requer decoração porque carece de frisos. Reequacionando algumas das qualidades essenciais da decoração e alguns dos seus porquês, pode-se captar com maior profundidade o espírito arquitetónico em geral e o moderno em particular.

A luz de um cristal não pode ser isolada da sua forma; a decoração é um aspeto congenial da arquitetura. Não se pode ter energia sem matéria; da mesma maneira não se pode ter decoração sem ornamento. Os frisos, os arabescos e as modinaturas são instrumentos do ornamento, mas um contraponto de planos curvos, uma parede branca, uma textura de tijolo à vista, uma superfície monocromática, são formas igualmente válidas de decoração." 514

513 A propósito deste enigmático projeto, Rossi sugere que "a forma que já não é geometria ou simples função (...) é - em Loos - usada como elemento de composição (...)."Na nossa perspetiva, o projeto para o Chicago Tribune apenas confirma a natureza albertiana do ornamento na arquitetura do autor.

ALDO ROSSI, "La Arquitetura de Adolf Loos", p. 15.

514 ERNESTO NATHAN ROGERS, Experiencia de la Arquitetura (Esperienza dell'architetura), Buenos Aires, Ediciones Nueva Visión, 1965 ( $1^{\text {a }}$ ed. 1958), p. 81. 
Se - como pensamos - Rogers tiver razão, o ornamento como recurso foi atualizado pela abstração de uma parede pintada, na qual a cor é o ornamento e a decoração a sua exteriorização formal. E, significativamente, sem prescindir da ideia albertiana de ornamento, bem como das condições impostas por Loos para a sua supressão:

“A orquestração, a medida, a relação recíproca destes instrumentos constitui a atividade específica da decoração, do mesmo modo que as relações entre os instrumentos práticos (materiais e medidas físicas) são atos de energia construtiva. A decoração interpreta os instrumentos práticos e confere-lhes validez estética no tempo." 515

Ou seja, materiais e medidas físicas - i.e. os atos de energia construtiva - constituem a beleza primária e inata, na aceção de Alberti, enquanto a orquestração, a medida e a sua relação recíproca - i.e. a decoração - constituem o ornamento enquanto beleza complementar e subsidiária, também na aceção de Alberti (refira-se, a propósito, a coincidência da medida enquanto variável comum da beleza inata e do ornamento). A diferença, porém, é que para Rogers um contraponto de planos curvos, uma parede branca, uma textura de tijolo à vista, uma superfície monocromática, são formas igualmente válidas de decoração - ideia que clarifica a posição aparentemente contraditória de Loos ao defender, simultaneamente, a supressão do ornamento e o ornamento clássico.

A este propósito Rogers sublinhará a importância da tradição, em consonância com o ponto de vista de Loos:

"Enquanto as formas construtivas surgem da interpretação puramente técnica, a decoração estabelece uma tradição, sem se preocupar criticamente com a justificação das formas." 516

"Preferimos antes uma decoração que exalte o objeto na sua dimensão real: que um copo seja um copo e uma cidade uma cidade. Isto

\footnotetext{
515 ERNESTO NATHAN ROGERS, op. cit., p. 81.

516 Ibidem, p. 82, 83.
} 
não significa sacrificar o objeto mas expressar a sua realidade sem analogias nem alegorias. Quando, há cinquenta anos, Adolf Loos escreveu Ornamento e Delito, o aspeto delituoso do ornamento identificava-se com a aberração voluntária das características do objeto (por uma fuga analógica ou por uma extrapolação alegórica). Hoje, quando rebocamos um muro, estamos a ornamentar intencionalmente e a assinalar o valor essencial do plano da parede; um muro de tijolo à vista, ainda que sem frisos, não é menos decorativo: o desenho regular, o tom natural do tijolo, o seu valor táctil pode possuir uma forte tensão expressiva. Para nós é suficiente, para a coerência da nossa linguagem, que a ação decorativa - ainda que livre na escolha do ornamento - não distorça o caráter dos objetos, mas antes, ajude a expressá-lo e a exaltar o seu significado." 517

Nas épocas coletivas, arquitetura e decoração tendem a um equilíbrio e a um classicismo; cliente e artista sacrificam-se então perante uma conceção objetiva da obra de arte, cuja beleza perfeita é, para dizer como Winckelmann, como a água pura que não tem nenbum sabor particular. ${ }^{518}$

Ao atualizar o problema do ornamento antigo através da ideia de decoração moderna, Rogers empreende a mais significativa operação de resgate em relação à ideia albertiana de ornamento. O autor não fala explicitamente nas características do ornamento albertiano. ${ }^{519}$ Porém, a sua

517 Ibidem, p. 89, 90.

518 Ibidem, p. 89.

519 Rogers identifica três possibilidades para enfrentar o problema da decoração. A primeira "consiste em negar através do ornamento a realidade construtiva, criando surpresas e ilusões" (o Barroco). A segunda, "pelo contrário, tende a exaltar expressivamente, através do ornamento, a realidade construtiva enfatizando os seus elementos (Brunelleschi, Francesco di Giorgio, etc.)." A terceira, "dialeticamente entre as outras duas, procura através do ornamento exteriorizar a obra de arte, não apenas na sua dimensão objetiva e estrutural, mas desdobrando o tema e, com frequência, idealizando-o literariamente. O espírito místico de um templo egípcio está implícito na disposição da planta; a organização social de Roma pode reconstruir-se a partir da distribuição urbana do fórum ou da estrutura da casa de Pompeia: se a cada função da arquitetura corresponde um determinado organismo, quer dizer, uma determinada lógica, parece claro, em relação a este terceiro ponto de vista, que o espírito da obra, a sua função bistórica, o seu sentimento ético, são explicáveis pelo ornamento."

A última hipótese é claramente a preferida de Rogers, ainda que, como ele próprio reconhece, contenha os seus perigos (a Fontana de Trevi) e também as suas obras-primas (o Partenon).

ERNESTO NATHAN ROGERS, op. cit., p. 84, 85. 
leitura das várias saídas para o problema da decoração, não deixa margem para dúvidas: a energia decorativa de Rogers é o ornamento de Alberti.

Poder-se-ia, agora, analisar as ressonâncias albertianas num arquiteto ativo hoje. Isto é, cremos que estarão agora reunidas as condições para as dar a ver, na teoria e na prática, num arquiteto como Giorgio Grassi. Ficará, porém, para outra ocasião.

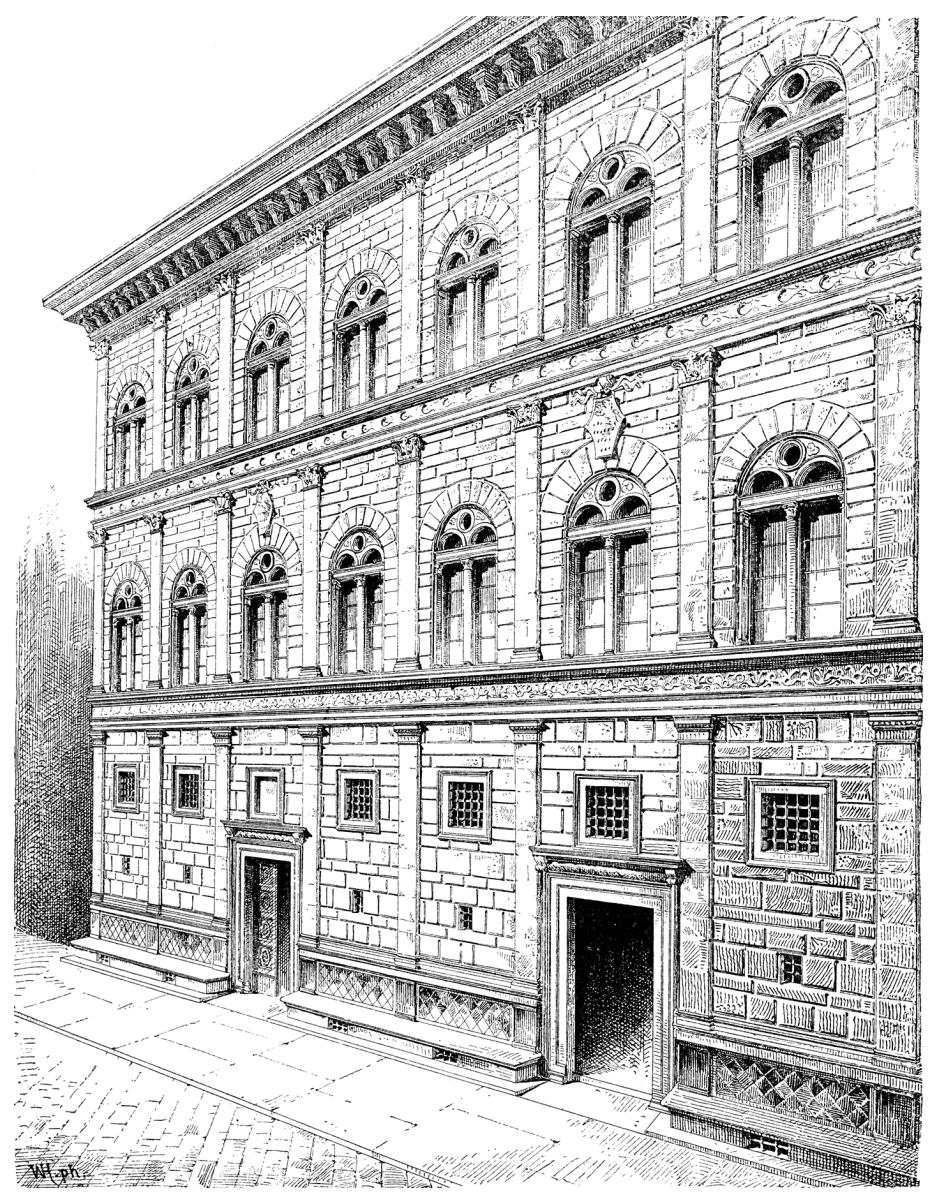

Fig. 1 - WILhElM LÜBKE, MAX SEMRAU, Desenho do Palazzo Rucellai (de acordo com a realidade construída por Alberti), 1908. Fonte: http://commons.wikimedia.org/wiki/File:Rucellai. jpg? uselang $=i t$ 


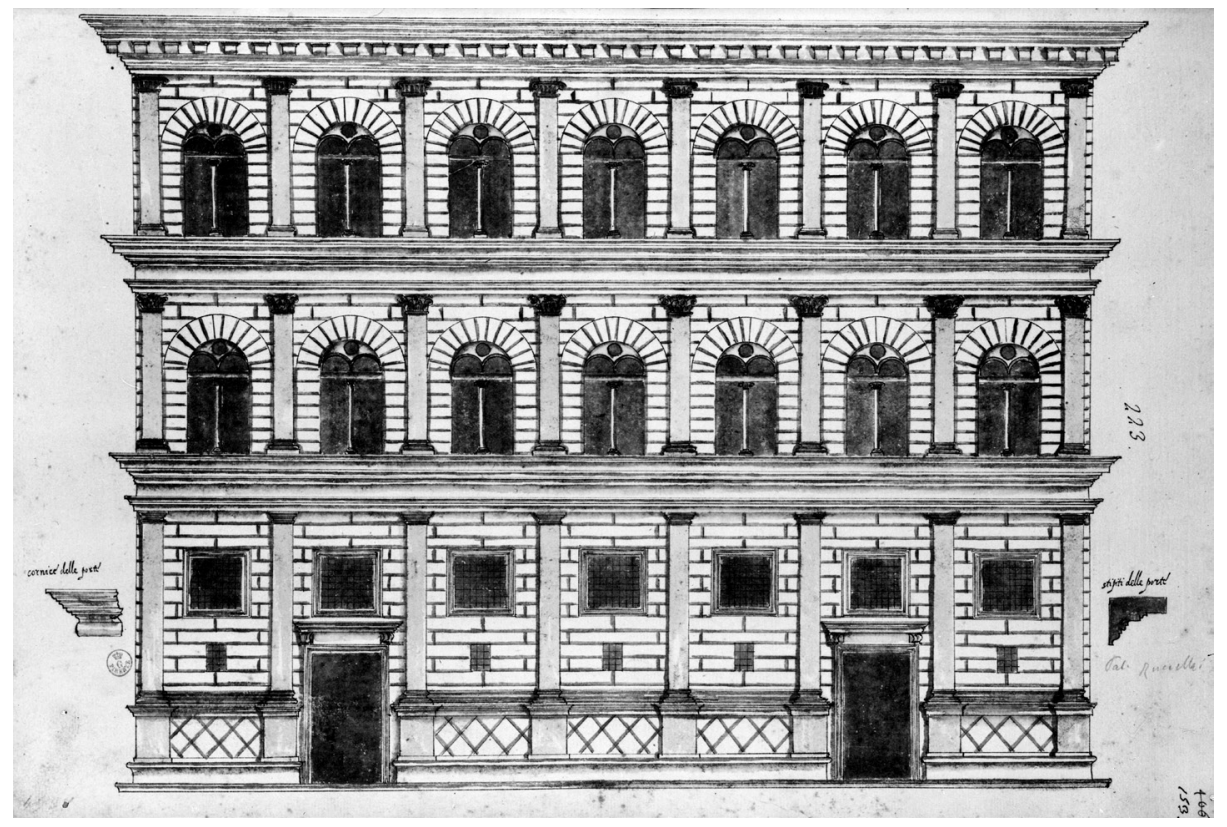

Fig. 2 - GIORgIO VASARI IL GIOvANe, Desenho do Palazzo Rucellai (versão "alterada e corrigida" pelo autor), 1600 aprox. Fonte: (C) Firenze, Gabinetto Disegni e Stampe degli Uffizi (inv. n. ${ }^{\circ} 4937$ A) 